\title{
Thermodynamic and Theoretical Studies of the Imide
} Derivatives

\author{
Hasan R. Obayes ${ }^{1}$, Ahmed A. Al-Amiery ${ }^{1, *}$, Mohammed S. Ali ${ }^{1}$, Ghadah H. Alwan ${ }^{2}$ \\ 1 University of Technology, Baghdad, Iraq; drh_obayes@yahoo.com (H.R.O.) \\ 2 Ministry of sciences and Technology, Industrial Research \& Development directorate, Industrial \\ Applications center, Baghdad, Iraq; gh6_alfrajy@yahoo.com \\ * Correspondence: dr.ahmed1975@gmail.com; Tel.: +96-47700-671-115
}

\begin{abstract}
Based on DFT (density functional theory) using B3LYP/6-31G method, theoretical investigations applied to demonstrate the structural, electronic properties and stability of $\left(\mathrm{N}, \mathrm{N}^{\prime}\right.$ (1,4-phenylene)bis(1,8-naphthalimide)) is more stable than the compound ( $\mathrm{N}$-(4-amino phenyl)1,8naphthalimide) by (-1.2762 eV or $-29.4299 \mathrm{Kcal} . \mathrm{mol}-1)$ depending on the values of HOMO, synthesis reaction of imide is spontaneous and endothermic at temperature $275^{\circ} \mathrm{C}$ according to the values of $\Delta \mathrm{rS}, \Delta \mathrm{rG}$ and $\Delta \mathrm{rH}$.
\end{abstract}

Keywords: imide; DFT; HOMO; spontaneous; endothermic

\section{Introduction}

Cyclic imides are important family of organic compounds possess structural features which confer potential biological activity and pharmaceutical use [1,2]. Their molecules contain an imide ring with a general structure [-CO-N(R)-CO-], so that they are hydrophobic and neutral and can therefore cross biological membranes in vivo. A diversity of biological activities and pharmaceutical uses have been attributed to them, such as antibacterial, antifungal, anti-nociceptive, anticonvulsant and antitumor [3]. The preparation of imides has received considerable attention during recent year A number of methods such as acylation of amides with acyl chlorides, anhydrides and carboxylic esters or acids [4-6], amino carbonylation of aryl bromides [7], reaction of azalactones with oxygen and palladium [8] have been reported for the preparation of acyclic imides. However, most of these methods suffer from drawbacks such as long reaction times, low yields, high temperature and producing side-products. Organic reactions assisted by microwave irradiation have attracted considerable attention in recent years [9-13]. The main benefits of the microwave reactions are much improved reaction rates, higher yields and formation of cleaner products. A noteworthy advantage of modern scientific microwave apparatus is the ability to control reaction parameters such as temperature, pressure and reaction times accurately.

\section{Results}

Reaction p-Phenylene diamine with 1,8-Naphthalic anhydride produces imide, this reaction has been studied theoretically depending by density function theory, in the light of the active groups in the reactants there is the possibility of the production of two imides compounds are (Imide1 and Imide2). Showed the electronic properties of these products that compound (Imide2) is more stable than the compound (Imide1) by (-1.2762 eV or -29.4299 Kcal.mol-1) depending on the values of high occupied molecular orbital (HOMO) in the table (1). Comparing the values gap energy for two compounds (Imide1 and Imide2) are: $(2.8314 \mathrm{eV}, 4.0104 \mathrm{eV})$ respectively, shows us that the compound (Imide2) is more stable because the greater the value of gap energy leads to increased stability $[20,21]$.

Thermodynamic study of the reaction has been made through calculation of the change in enthalpy $(\Delta \mathrm{rH})$, the change in entropy $(\Delta \mathrm{rS})$ and the change in Gibbs energy $(\Delta \mathrm{rG})$ of the reaction at two temperature (room temperature $25^{\circ} \mathrm{C}=298^{\circ} \mathrm{K}$ and temperature $275^{\circ} \mathrm{C}=548^{\circ} \mathrm{K}$ ), in figure (1) reaction 
(1) and reaction (2) at room temperature $25^{\circ} \mathrm{C}=298^{\circ} \mathrm{K}$ are not spontaneous according to the values of $\Delta \mathrm{rS}$ (negative value) and $\Delta \mathrm{rG}$ (positive value) thermodynamically not favoured; instead the reverse is favoured, but from values of $\Delta \mathrm{rH}$ the reaction (1) endothermic (positive value) and reaction (2) exothermic (negative value). While figure (2) both reactions are spontaneous and endothermic according to the values of $\Delta \mathrm{rS}$ (positive value), $\Delta \mathrm{rG}$ (negative value) thermodynamically favoured and $\triangle \mathrm{rH}$ (positive value) [22,23]. In figure (3) the HOMO and LUMO electronic distributions for reactants (p-Phenylene diamine and 1,8-Naphthalic anhydride), showing the mechanism of reaction between reactants, in HOMO of $\mathrm{p}$-Phenylene diamine as we note the concentration of electron density on the nitrogen atoms that is attack the carbon atoms in the carbonyl group in HOMO of 1,8Naphthalic anhydride to produce imide in the last. We conclude that synthesis reaction of imide compounds needs to heat up to $275^{\circ} \mathrm{C}$ and the reaction (2) more stable than reaction (1) thermodynamically.

Table 1: Physical values of all molecules were calculated with B3LYP/6-31G.

\begin{tabular}{|c|c|c|c|c|c|c|c|}
\hline \multirow[t]{2}{*}{ Molecules } & \multicolumn{2}{|c|}{$\begin{array}{c}\text { Enthalpy (H) } \\
\text { Kcal.mol }^{-1}\end{array}$} & \multicolumn{2}{|c|}{ 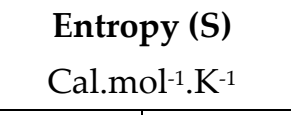 } & \multirow[t]{2}{*}{$\begin{array}{c}\text { Еномо } \\
\mathrm{eV}\end{array}$} & \multirow[t]{2}{*}{$\begin{array}{c}\text { ELumo } \\
\mathrm{eV}\end{array}$} & \multirow{2}{*}{$\begin{array}{c}\text { Gap energy } \\
\text { (Ецuмо-Еномо) } \\
\text { eV }\end{array}$} \\
\hline & $298 \mathrm{~K}$ & $548 \mathrm{~K}$ & $298 \mathrm{~K}$ & $548 \mathrm{~K}$ & & & \\
\hline water & 14.670 & 16.226 & 45.142 & 50.126 & -7.8807 & 1.4370 & 9.3177 \\
\hline p-Phenylene diamine & 88.537 & ----- & 80.177 & ------ & -4.1514 & 0.5440 & 4.6954 \\
\hline $\begin{array}{l}\text { 1,8-Naphthalic } \\
\text { anhydride }\end{array}$ & 101.367 & ------ & 98.578 & ------ & -7.0094 & -2.9535 & 4.0559 \\
\hline Compound (Imide 1) & 175.306 & 197.958 & 130.524 & 185.507 & -5.2366 & -2.4052 & 2.8314 \\
\hline Compound (Imide 2) & 261.180 & 296.622 & 177.613 & 262.922 & -6.5128 & -2.5024 & 4.0104 \\
\hline
\end{tabular}

Figure (1). The reaction of synthesis new derivative imide and values of $\Delta \mathrm{rH}, \Delta \mathrm{rS}$ and $\Delta \mathrm{rG}$ at room temperature $25^{\circ} \mathrm{C}=298^{\circ} \mathrm{K}$.

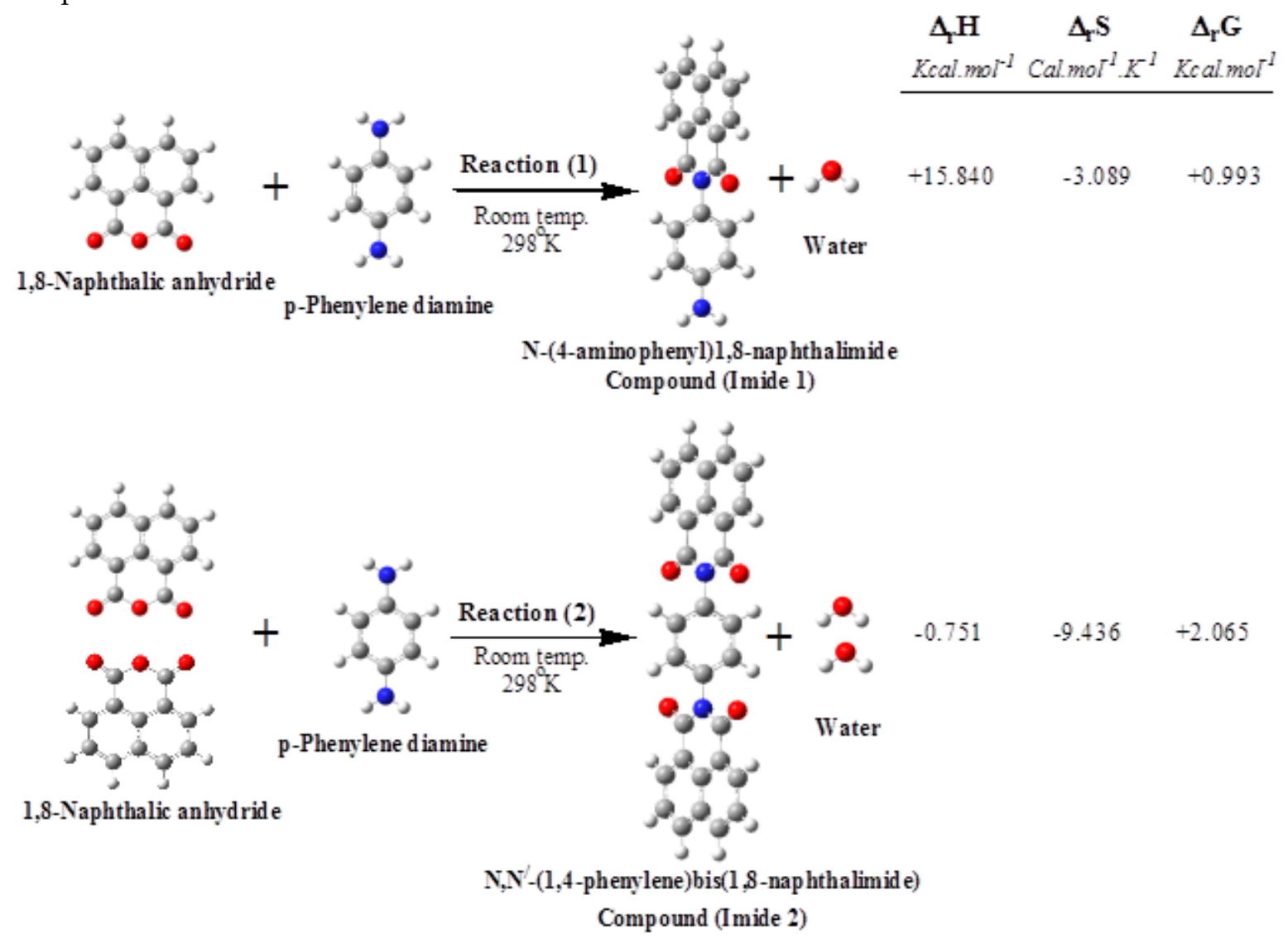


Figure (2). The reaction of synthesis new derivative imide and values of $\Delta \mathrm{rH}, \Delta \mathrm{rS}$ and $\Delta \mathrm{rG}$ at temperature $275^{\circ} \mathrm{C}=548^{\circ} \mathrm{K}$.

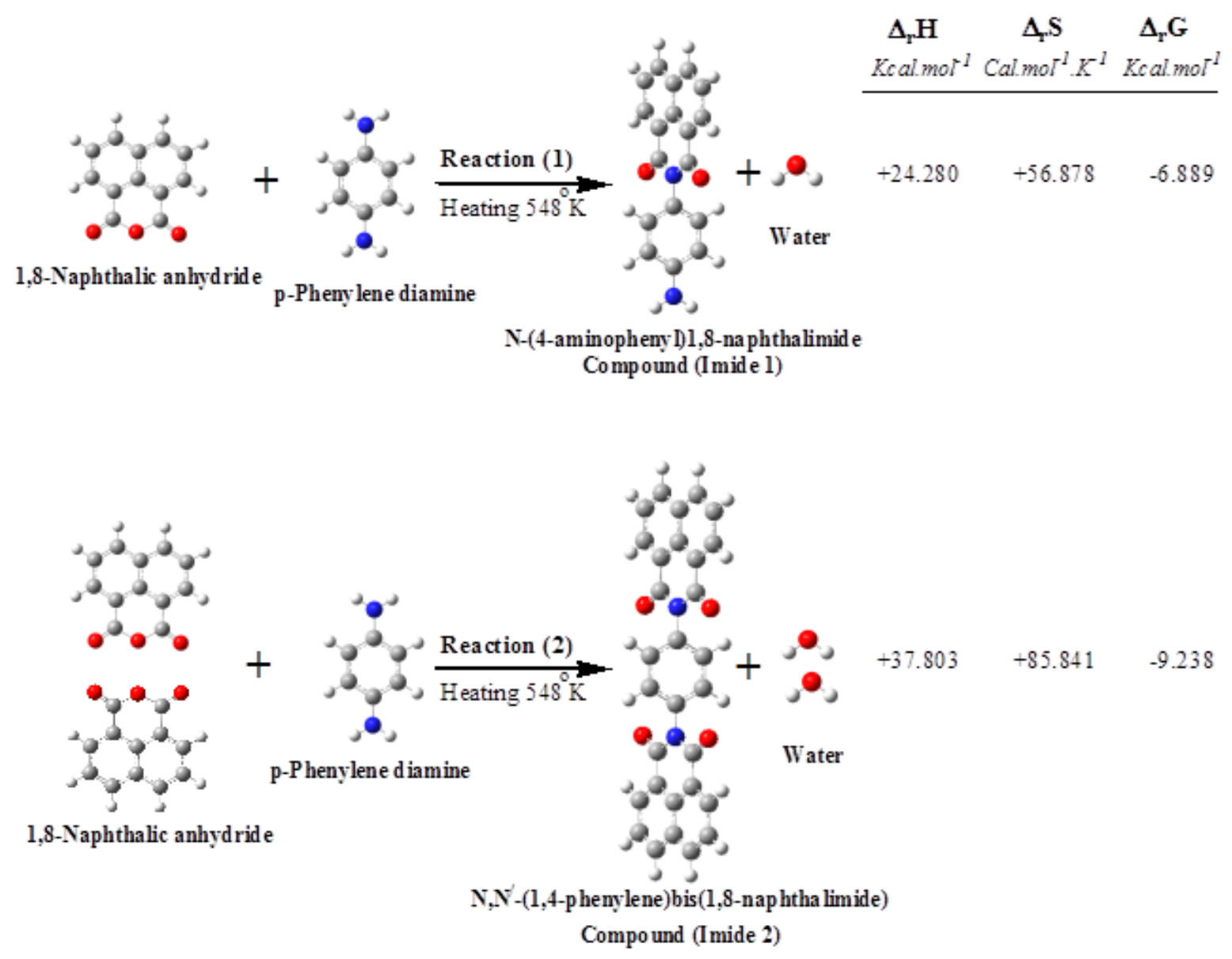

Figure (3). HOMO and LUMO of reactants (p-Phenylene diamine and 1,8-Naphtha

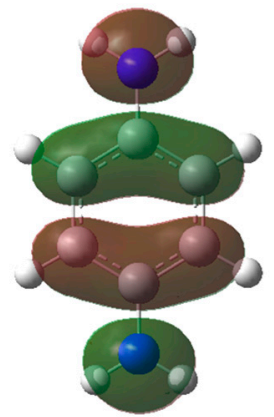

HOMO

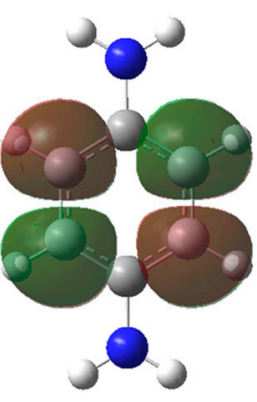

LUMO

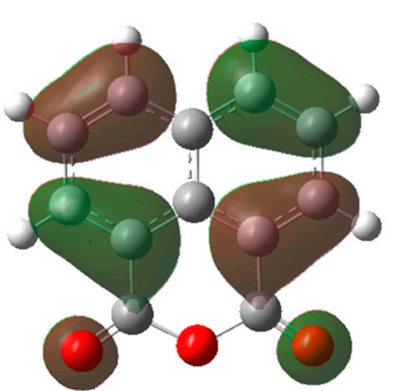

HOMO

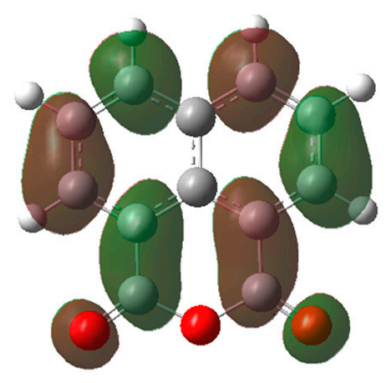

LUMO

p-Phenylene diamine

1,8-Naphthalic anhydride 


\section{Materials and Methods}

\section{Computational Methods}

Molecular geometries of the all molecules were fully optimized with the hybrid density functional theory (DFT) B3LYP method[14-16] using the 6-31G basis set[17,18] by means of the Gaussian 09, revision A.02[19] used for all geometry optimizitions, thermodynamic functions at conditions (temperature $=298^{\circ} \mathrm{K}, 548^{\circ} \mathrm{K}$, and pressure $=1.0 \mathrm{Atm}$ ), high occupied molecular orbital (HOMO) and low unoccupied molecular orbital (LUMO) distribution, and some physical properties for all molecules.

\section{Conclusions}

The quantum chemistry calculations using the density function theory (DFT) method to thermodynamic study of production reaction of two imides compounds at room temperature $25^{\circ} \mathrm{C}=298^{\circ} \mathrm{K}$ and temperature $275^{\circ} \mathrm{C}=548^{\circ} \mathrm{K}$. The results showed that the reaction needs to heat up to $275^{\circ} \mathrm{C}$ to be spontaneous and endothermic, compound (Imide2) is more stable than compound (Imide1) depending on the values of high occupied molecular orbital (HOMO).

Acknowledgments: This study was supported by University of Technology/ Iraq.

Author Contributions: H.R.O. conceived and designed the work; G.H. A. performed the calculations; M.S. analyzed the data; A.A.A. wrote the paper.

Conflicts of Interest: The authors declare no conflict of interest.

\section{References}

1. A. D. Andricopulo, R. A .Yunes, V.C. Filho, R. J. Nunes, J. W. Frazer and E. H. Cordes, Pharmazi, 54 (9), pp.698, 1999.

2. E. O .Lima, E .F. Queiroz, A. D. Andricopulo, R. J. Nunes, R. A. Yunes, R. Correa and V. C. Filho, Bol. Soc. Chil. Quim, 44 (2) pp.185, 1999.

3. D. S. Stiz, M. M. Souza, V. Golin, R. A. S .Neto, R. Correa, R .J. Nunes,, R. A. Yunes and V. C. Filho, Pharmazie, 55 (12) pp.942, 2000.

4. D. Davidson, H. Skovronek, J. Am. Chem. Soc., 80 pp. 376, 1958.

5. C. D. Hurd, A. G. Prapas, J. Org. Chem. 24 pp. 388, 1959.

6. W. S. Durrell, J. A. Young, R. D. Dresdner, J. Org. Chem. 28 pp. 831, 1963.

7. A. Schnyder, A. F. Indolese, J. Org. Chem. 67 pp. 594, 2002.

8. R. B. Bates, F. A. Fletcher, K. D. Janda, W. A. Miller, J. Org. Chem. 49 pp. 303, 1984.

9. R. S. Varma, Green Chem. 1 pp. 43, 1999.

10. C. O. Kappe, Angew. Chem. Int. Edit. 43 pp. 6250, 2004.

11. M. Nüchter, B. Ondruschka, W. Bonrath, A. Gum, Green Chem. 6 pp. 128, 2004.

12. I. Mohammadpoor-Baltork, A.R. Khosropour, S. F. Hojati, Catal. Commun. 8 pp. 200, 2007.

13. M. Moghadam, I. Mohammadpoor-Baltork, V. Mirkhani, S. Tangestaninejad, M. Abdollahi-Alibeik, B.H. Yousefi, H. Kargar, Monatsh. Chem. 138 pp. 579, 2007.

14. A. D. Becke, "Density-functional exchange-energy approximation with correct asymptotic behavior," Physical Review, vol. 38, pp. 3098-3100, 1988.

15. A. D. Becke, "Density-functional thermochemistry-III. The role of exact exchange," The Journal of Chemical Physics, vol. 98, no. 7, pp. 5648-5652, 1993.

16. C. Lee, W. Yang, and R. G. Parr, "Development of the Colle-Salvetti correlation-energy formula into a functional of the electron density," Physical Review, vol. 37, pp. 785-789, 1988.

17. W. J. Pietro,M.M. Francl,W. J. Hehre, D. J. Defrees, J. A. Pople, and J. S. Binkley, “Self-consistent molecular orbital methods. 24. Supplemented small split-valence basis sets for second-row elements," Journal of the American Chemical Society, vol. 104, no. 19, pp. 5039-5048, 1982. 
18. K. D. Dobbs and W. J. Hehre, "Molecular orbital theory of the properties of inorganic and organometallic compounds 5. Extended basis sets for first-row transition metals," Journal of Computational Chemistry, pp. 861-879, 1987.

19. J. A. Pople, M. J. Frisch, G. W. Trucks, H. B. Schlegel, G. E. Scuseria, et al., “Gaussian 09W (Revision A.02),” Gaussian Inc., Wallingford CT 06492, USA, 2009.

20. A. A. Al-Amiery, H. D. Jaffar, H. R. Obayes et al., "Thermodynamic studies on 4-aminocoumarin tautomers," International Journal of Electrochemical Science, vol. 7, pp. 8468-8472, 2012.

21. J. H. Naama, G. H. Alwan, H. R. Obayes et al., "Curcuminoids as antioxidants and theoretical study of stability of curcumin isomers in gaseous state," Research on Chemical Intermediates, vol. 39, no. 9, pp. 4047-4059, 2013.

22. H. R. Obayes, A. A. Al-Amiery, H. D. Jaffar, A. Y. Musa, A. H. Kadhum, and A. B. Mohamad, “Theoretical Study for the Preparation of Sub-Carbon Nano Tubes from the Cyclic Polymerization Reaction of Two Molecules from Corannulene, Coronene and Circulene Aromatic Compounds" J. Comput. Theor. Nanosci. 10, pp. 2459-2463, 2013.

23. H. R. Obayes, G. H. Alwan, A. A. Al-Amiery, A. H. Kadhum and A. B. Mohamad, “Thermodynamic and Theoretical Study of the Preparation of New Buckyballs from Corannulene, Coronene, and Circulene" Journal of Nanomaterials, 2013, Article ID 451920, 8 pages 2013.

(C) 2016 by the authors; licensee Preprints.org, MDPI, Basel, Switzerland. This article is an open access article distributed under the terms and conditions of the Creative Commons by Attribution (CC-BY) license (http://creativecommons.org/licenses/by/4.0/). 